\title{
PREVALÊNCIA DE ANTICORPOS CONTRA AGENTES VIRAIS EM EQUÍDEOS NO SUL DO ESTADO DE SÃO PAULO
}

\author{
E.M.S. Cunha ${ }^{1}$, E.M.C. Villalobos ${ }^{1}$, A.F.C. Nassar ${ }^{1}$, M.C.C.S.H. Lara ${ }^{1}$, \\ N.F. Peres ${ }^{2}$, J.P.C. Palazzo ${ }^{2}$, A. Silva ${ }^{2}$, E. De Stefano ${ }^{1}$, F.A. Pino ${ }^{3}$
}

${ }^{1}$ Instituto Biológico, Centro de Pesquisa e Desenvolvimento de Sanidade Animal, Av. Cons. Rodrigues Alves, 1252, CEP 04014-002, São Paulo, SP, Brasil. E-mail: cunha@biologico.sp.gov.br

\section{RESUMO}

Foram analisados soros de 163 equídeos (143 equinos e 20 muares) provenientes de 16 municípios do sul do Estado de São Paulo, parte no Vale do Ribeira e parte no litoral. Utilizouse uma amostra probabilística estratificada em dois estágios, sendo a unidade amostral de primeiro estágio constituída pela unidade de produção agropecuária(UPA) e a de segundo estágio pelo animal dentro da UPA sorteada. Os soros foram coletados no período de outubro de 2004 a junho de 2005. Foram estimadas as prevalências de anticorpos contra os vírus das encefalites equinas do tipo leste (EEE), oeste (WEE) e venezuelana (VEE), herpesvírus equino (HVE), arterite viral dos equinos (AVE), influenza equina 1 e 2 (IE-1 e 2) e estomatite vesicular Indiana 2 - Cocal (COCV) eIndiana 3 - Alagoas (VSAV). Foram utilizadas as técnicas de inibição da hemoaglutinação para a detecção de anticorpos contra os vírus IE-1 e 2 e de soroneutralização para os demais vírus estudados. Dos animais testados, $26 \%$ apresentaram anticorpos contra o HVE, $21 \%$ para COCV, $5 \%$ para VSAV, $16 \%$ para EEE, 2,26\% para VEE, $11 \%$ para influenza Equi $/ 2$ e 2,7\% para influenza Equi/1. Não se encontraram animais reagentes para WEE e AVE. A soroprevalência obtida sugere a circulação do HVE, dos vírus da IE Equi-1(H7N7) e Equi-2 (H3N8), dos vírus EEE e VEE e dos vírus da estomatite vesicular Indiana 2 - Cocal (COCV) e Indiana 3 - Alagoas (VSAV) no rebanho de equídeos do sul do Estado de São Paulo.

PALAVRAS-CHAVE: Equídeos, prevalência, anticorpos, vírus, Estado de São Paulo.

\section{ABSTRACT}

SEROPREVALENCE OF VIRAL DISEASES IN EQUIDAE FROM THE SOUTH OF SÃO PAULO STATE, BRAZIL. Sera from 163 Equidae (143 equines and 20 mules) from 16 municipalities in the southern region of São Paulo State, Brazil, were selected in a two-stage stratified probabilistic sample survey. Serum samples were collected from October 2004 to June 2005. The antibody prevalence was estimated against eastern (EEE), western (WEE) and Venezuelan (VEE) equine encephalitis, equine herpesvirus (EHV), equine viral arteritis (EVA), equine influenza 1 and 2 (EI1 and 2) and vesicular stomatitis (Indiana 2 Cocal virus - COCV and Indiana 3 - Alagoas virus (VSAV). The results showed positivity of $26 \%$ for EHV, $21 \%$ for COCV , $5 \%$ for VCAV, $16 \%$ for EEE, $2.26 \%$ for VEE, $11 \%$ for influenza Equi/2 and 2.7\% for influenza Equi/1. No antibodies were detected against WEE and AVE. These results suggest that the equine population in the south of São Paulo State is exposed to infection risk of HVE, IE Equi-1(H7N7) and Equi-2 (H3N8), EEE, VEE and Indiana 2 - Cocal (COCV) Indiana 3 - Alagoas (VSAV).

KEY WORDS: Equidae, prevalence, antibodies, virus, São Paulo State.

\section{INTRODUÇÃO}

Orebanho equino do Brasil, em 1991, foi estimado pelo IBGE em 6.236.607 cabeças, sendo que grande parte, ou seja, $1.788 .190(28,7 \%)$ era criada ou mantida na região sudeste do país, contando o Estado de São
Paulo com uma cifra equivalente a 609.406 (9,8\% do total) espécimes. Com base em dados censitários do projeto LUPA de 1995/96 (Pino et al., 2000), o Vale do Ribeira conta com uma população de 10.552. equídeos, distribuídos na zona rural e urbana. Esta população está distribuída em 2.606 propriedades, com média de

${ }^{2}$ Defesa Agropecuária, São Paulo, SP, Brasil.

${ }^{3}$ Instituto de Economia Agrícola, São Paulo, SP, Brasil. 
quatroanimais, confirmandoa existência de pequenas propriedades de subsistência. Desta maneira, qualquer agravo de saúde dos animais leva aos proprietários grandes prejuízos, pois dependem destes equinos para a lida diária, bem como para o transporte.

Dentre as doenças que acometem os equídeos, as viroses assumem papel importante do ponto de vista sanitárioeeconômico, podendo-sedestacar:asencefalites causadas por Alphavírus, a influenza, a arterite viral, a estomatite vesicular e as infecções herpéticas.

Os herpesvírus equinos podem causar doença respiratória, neurológica e reprodutiva, com abortamento e mortalidade perinatal de potros. Estes diferentes tipos deenfermidades podem ocorrer associados ou não (REED; ToRibio, 2004). É considerada como uma das enfermidades que mais causa prejuízos para a criação de equinos, principalmente quando ocorrem epidemias de aborto (REED;TORIBIO, 2004). A arterite viral dos equinos, da mesma forma que os herpesvírus, pode causar doença respiratória, morte em potros e abortamentos (HoLYOAK et al., 2008).

A influenza é considerada uma das mais importantes doenças respiratórias causadas por vírus nas criações de equinos por ser altamente contagiosa. Dois subtipos do vírus da influenza A, equino-1(H7N7) e equino-2 (H3N8), são responsáveis pela doença. Alguns estudos mostraram que o vírus está disseminado na população equina do Brasil (Oliveira et al.,2005; MANCINI et al., 2006).

São poucos os estudos que investigam a ocorrência dos Alphavírus em equídeos no Brasil (LOPES;SACHETA, 1974; КотAIT etal., 1992;Iversson etal., 1993; Silvaetal., 1999; Heinemann et al., 2006), apesar de ser conhecido que alguns vírus desta família são endêmicos em várias regiões (IVERSSON; COIMBRA, 1984; VASCONCELOS et al., 1991; Heinemann et al., 2006). O vírus do tipo leste tem sido esporadicamente isolado de animais com sintomatologia nervosa (NILSSON;SUGAY, 1962; KоTAIT et al., 1992). Em São Paulo, na região do Vale do Ribeira, na década de 1970 ocorreu uma epidemia de encefalite porarbovírusemhumanosquedeixou umacentena de mortos e sequelas em muitos moradores da região (IVERSSON; COIMBRA, 1984). Nesta mesma região,estudos mostraram a ocorrência de encefalite causada pelo complexo VEE em soldados que haviam retornado de treinamento em área silvestre e inquérito sorológico realizado em moradores de reserva ecológica detectou a presença de anticorpos para os vírus EEE e VEE (ROMANO-LIEBER; IVERSSON, 2000).

A estomatite vesicular é uma doença de grande importância econômica devido às barreiras comerciais, quarentenas e queda na produtividade dos animais acometidos. É de incidência sazonal, ocorre após as chuvas em regiões de clima tropical com a participação de insetos na cadeia epidemiológica (TESh et al., 1987; ACHA ; SzYFRES, 2003).
Tendo em vista a importância dos equídeos para diferentes atividades da região, relacionadas à lida com bovinos, transporte e extrativismo, bem como a falta de informações sobre as doenças que acometem estes animais, o objetivo do presente estudo foi avaliar a prevalência de anticorpos para agentes virais que acometem equinos e muares da região sul do Estado de São Paulo.

\section{MATERIAL E MÉTODOS}

Oestudo abrangeu 16 municípios do sul do Estado deSão Paulo, parte no vale do Ribeira e parte no litoral: Apiaí, Barra do Turvo, Cajati, Cananéia, Capão Bonito, Eldorado, Iguape, Iporanga, Itariri,Jacupiranga, Juquiá, Miracatu, Pariqueraçu, Pedro de Toledo, RegistroeSete Barras (Tabela 1). Nesses municípios havia equídeos em 2.606 (24,1\%) unidades de produção agropecuária (UPA), em um total de 10.522 cabeças. O número de cabeças por UPA variava de 1 a 130, com média igual a 4, sendo que a metade das UPAs com equídeos possuía apenas um ou dois animais e $90 \%$ delas possuía no máximo 8 animais. Para encontrar os animais dos quais foram colhidas amostras de sangue, utilizou-se uma amostra probabilística estratificada em dois estágios. A unidade amostral de primeiro estágio foi a UPA, que geralmente coincide com o conceito de imóvel rural (INCRA, 2002; PINO, 2003). A unidade amostral de segundo estágio foi o animal dentro da UPA sorteada. No primeiro estágio, as UPAs, que constituíam conglomerados desiguais de animais, foram estratificadas (Tabela 1), com base em dados censitários do projeto LUPA (PINo etal., 2000), obtendose quatro estratos de tamanho de plantel. No "estrato 0 ", incluíram-se as UPAs que não tinham equídeos, porque, entre a data do cadastramento das UPAs e a data da coleta de material poderia acontecer de essas unidades passarema teranimais. Foi previstoque, com os recursos disponíveis, seria possível levantar até 50 UPAse no máximo 20 animais em cada UPA. Fizeramsealgumas simulações a fim de dividir os 50 elementos amostrais do primeiro estágio entre os estratos, obtendo-se os valores adotados.

No segundo estágio, amostras de sangue foram colhidas em animais das UPAs sorteadas, segundo o seguinte esquema: a) em todos os animais, se fossem encontrados até 20 equídeos na UPA; b) em 20 animais sorteados, quando encontrados mais de 20 equídeos na UPA. A prevalência foi estimada segundo fórmulas usuais da Teoria de Amostragem, apresentadas em KısH (1965). Na apresentação dos resultados foram usadas porcentagens de animais infectados, expressas em porcentagem (prevalência). Nesse esquema, esperava-se encontrar 296 animais nas UPAs sorteadas. 
Tabela 1 - Número de UPAs (unidade de produção agropecuária) e de equídeos na população, por estrato, região sul do Estado de São Paulo, 1998-2003.

\begin{tabular}{|c|c|c|c|c|c|c|}
\hline \multirow[t]{2}{*}{ Estrato } & \multirow[t]{2}{*}{ Equídeos na UPA } & \multicolumn{4}{|c|}{ Tamanho da população } & \multirow[t]{2}{*}{ Tamanho da Amostra (UPAs) } \\
\hline & & UPAs & Equinos & $\begin{array}{l}\text { Asininos e } \\
\text { muares }\end{array}$ & $\overline{\text { Equídeos }}$ & \\
\hline 0 & 0 & 8.201 & 0 & 0 & 0 & 2 \\
\hline 1 & 1 a 5 & 2.147 & 4.644 & 399 & 5.043 & 37 \\
\hline 2 & 6 a 20 & 418 & 3.469 & 390 & 3.859 & 7 \\
\hline 3 & 21 ou mais & 41 & 1.463 & 157 & 1.620 & 4 \\
\hline Soma & - & 10.807 & 9.576 & 946 & 10.522 & 50 \\
\hline
\end{tabular}

Fonte:Secretaria de Agricultura e Abastecimento do Estado deSão Paulo, Projeto LUPA, atualizado pela Coordenadoria de Assistência Técnica Integral (CATI), conforme Pino et al. (2000).

As amostras foram colhidas no período de outubro de 2004 a junho de 2005. Para a obtenção de soro sanguíneo foram colhidas amostras de $10 \mathrm{~mL}$ de sangue, em tubos de vidro tipo Vacutainer $\mathrm{BD}^{\circledR}$ pela punção da veia jugular externa. As amostras de soro foram separadas em alíquotas em tubos plásticos e congeladas à temperatura de $-20^{\circ} \mathrm{C}$ até o momento da realização das provas de sorodiagnóstico.

Para a pesquisa de anticorpos neutralizantes contra os vírus das encefalites equinas do tipoleste (EEE), oeste(WEE) evenezuelana(VEE), herpesvírus equino (HVE), arterite viral dos equinos (AVE) e estomatite vesicular tipos COCV e VSAV foi utilizada a soroneutralização (SN). Os soros foram testados em diluições na base 5 para detecção de anticorpos contra EEE, WEE, VEE e na base 2 para HVE-1, AVE e COCV e VSAV frente a 100-200/25 $\mu$ L DICT50 de suspensão dos vírus leste (cepa Tatuí), oeste (TR 25717), complexo venezuelano (SP AN 15600), HVE1 (A4/72) e AVE (amostra Bucyrus) e 1.000 DICT50/ $25 \mu \mathrm{L}$ dos vírus COCV e VSAV. Após a incubação, por 1 hora a $37^{\circ} \mathrm{C}$, foram adicionados $100-150 \mu \mathrm{L}$ de uma suspensão contendo 250.000/300.000 células/mL. Para os testes de EEE, WEE, VEE, HVE, e COCV e VSAV foi utilizada a linhagem de células VERO e para o teste de AVE células RK13. A leitura para as diferentes técnicas de SN foi realizada após 48-72 horas de incubação, em estufa com $5 \%$ de CO2 e a $37^{\circ} \mathrm{C}$, observando-se a neutralização do efeito citopático. Os títulos de anticorpos neutralizantes foram expressos em valores do inverso da diluição queneutralizou $100-200$ ou 1.000DICT50/ $25 \mu \mathrm{L}$ do vírus. Foram considerados reagentes os soros com título $\geq$ a 5 para os vírus EEE, WEE e VEE; $\geq$ a 4 para os vírus HVE e AVE; z a 32 para COCV e VSAV. (SENNE et al., 1985; KотAIT et al., 1989; КотAтт et al.,1992; OIE, 2006). A detecção de anticorpos contra o vírus da IE foi realizada pela técnica de inibição da hemaglutinação $(\mathrm{HI})$, realizada de acordo com o preconizado pela OIE (2006). Os soros foram testados frente aos antígenos tipo A/Eq1 (amostra SP/56) e tipo A/Eq2 (amostra SP/1/85) com 4 unidades hemaglutinantes (UHA) adicionando hemácia de galo $0,5 \%$. As amostras que apresentaram títulos deanticorposiguais ou superiores a 20UHI foram consideradas positivas.

\section{RESULTADOS E DISCUSSÃO}

Foramencontrados três animais em uma das UPAs do estrato 0, mas eles foram desconsiderados nas totalizações, pois as estimativas incluindo esse estrato mostraram-se muito ruins, porque a fração amostral era muito pequena. No estrato 1 foram encontradas 18 UPAs que não possuíam mais equídeos, o que também aconteceu em uma UPA do estrato 3. O número máximo de animais encontrados por UPA foi igual a 20 (contra 130 encontrados no levantamento censitário) e o número total de animais dos quais se recolheu amostra de sangue foi igual a 163, número menor do que os 296 que foram previstos na fase de delineamento da amostra, o que parece indicar tendência de redução desses animais na região considerada (Tabela 2).

Estimou-se que nas UPAs dos estratos 1 a 3 houvessem 7.763 animais (estatisticamente, esse número varia entre 4.786 e 10.740), o que representa diminuição de $26 \%$ em relação ao que havia por ocasião da elaboração do cadastro. Estimou-se que $87 \%$ dos equídeos eram equinos (entre $80 \%$ e $95 \%$ ) e que $53 \%$ eram machos (entre $47 \%$ e $59 \%$ ). A idade média dos animais foi estimada em 96 meses (8 anos). Dos 163 animais testados, $26 \%$ apresentaram anticorpos contra o HVE, 21\% para estomatite vesicular Indiana 2 Cocal(COCV) e $5 \%$ para o Indiana 3-Alagoas(VSAV), $16 \%$ para EEE, $2,26 \%$ para VEE, $11 \%$ para influenza Equi/2 e 2,7\% para influenza Equi/1. Não foram detectados animais reagentes para WEE e AVE. Já foi 
demonstrado por vários autores (VARGAS; WEIBLEIN, 1991; Silva et al., 1999; CunHa et al., 2002, HeINEMANN et al., 2002; LARA etal., 2003b;Dielet al.,2006)queoHVE está amplamente distribuído na população equina do Brasil. Os resultados obtidos no presente trabalho, que relatam uma porcentagem de $26 \%$ de animais reagentes, corroboram com os achados em outros estudos realizados no Estado de São Paulo (Modolo et al., 1989; KOTAIT et al., 1989; CUNHA et al., 2002; LARA et al., 2003b) e enfatizam a circulação do agente.

No presente estudo a análise de soros de equídeos da região sul do Estado de São Paulo não revelou nenhum animal reagente para AVE. Alguns inquéritos sorológicos mostraram que o vírus circula em populações de equinos em várias regiões do Brasil (LARA et al., 2002; LARA et al., 2003a; Diel et al., 2006), em contraponto com outros que não detectaram animais reagentes (LARA et al., 2006; HEINEMANN et al., 2002). Foi postulado por LARA et al. (2002) que a transmissão do vírus da arterite pode ser maior em animais utilizados para esporte, exposição e reprodução, pois estes animais são submetidos com frequência a condições de aglomeração o que facilitaria a transmissão pela via respiratória. Ainda, esta transmissão pode ocorrer com maior frequência em reprodutores submetidos à monta natural e inseminação artificial, já que garanhões soropositivos podem eliminar o vírus através do sêmen (HoLyOAK et al., 2008). Vale salientar que os animais envolvidos no presente estudo eram na grande maioria animais de lida e tração, o que pode explicar os resultados encontrados.

O presente estudo detectou uma prevalência de 2,7\% para o vírus $\mathrm{H} 7 \mathrm{~N} 7$ e $11 \%$ para o H3N8. Segundo LOUREIRO et al. (2000), apesar da influenza causada pelo vírus H7N7 não ser confirmada desde os anos 1980, existem evidências sorológicas de sua persistência na população equina o que está de acordo com os achados neste trabalho. Este fato foi também observado nas investigações feitas por MANCINI et al. (2006). Em relação ao H3N8, levantamento sorológico retrospectivo em equinos errantes do Estado do Rio de
Janeiromostrou que 35,9\% dosanimaiseram reagentes (Oliveira et al., 2005). Estudo realizado no Pantanal também detectou altas porcentagens de animais reagentes para os vírus H3N8/Miami e H3N8/ Fontainebleau (SILva et al., 1999). Os resultados obtidos sugerem que os vírus da influenza H7N7 e H3N8 circulam na região sul do Estado de São Paulo.

Os resultados apresentados neste estudo, realizado na mesma região, detectaram anticorpos contra o vírus EEE (16\%) e VEE (2,26\%) nos animais testados, e corroboram com os achados em humanos (ROMANOLIEBER;IVERSSON, 2000). Utilizando os mesmos animais amostrados neste estudo, Bissordiet al .(2006) encontraram $21,5 \%$ de animais com anticorpos contra o vírus Iguape, um flavivírus isolado em 1979 de animais sentinelas na cidade de Iguapelocalizada na região do Vale do Ribeira. Estes achados enfatizam a importância dos equídeos como animais sentinelas para monitorara circulaçãodearbovírus. Outrodadoapontado pelo estudo foi que a prevalência de anticorpos contra o EEE mostrou-se 16 vezes (IC-95\% 14,355$18,406)$ maior entre muares do que em equinos. Sabe-se que na região é comum a utilização de burros e mulas na coleta de palmito em áreas de mata o que permite maior contato destes animais com os mosquitos vetores.

A presença de anticorpos contra o vírus da estomatite vesicular em equinos, na ausência de sinais clínicos é comum, vista a endemicidade da doença, que reaparece nos animais domésticos praticamente a cada ano. Segundo registros daoIE, ocorreram sete surtos de estomatite vesicular no ano de 2004, com o envolvimento de 396 animais, sendoidentificado o vírus Indiana (OIE, 2007). Allende; GERMAnO (1993), ao analisarem amostras de soro de bovinos, equinos e suínos deáreas endêmicas no Brasil, encontraram 98,4\% (300/305) animais com anticorpos para o vírus Indiana 3. De Stefano et al. (2003) e OKUdA et al. (2003) encontraram cerca de $2 \%$ de animais com anticorpos para o tipo Indiana. Essa manutenção da resposta humoral nos equinos avaliados, na ausência de casos clínicos, pode ser explicada pela presen-

Tabela 2 - Número de UPAs (unidade de produção agropecuária) e de equídeos na amostra, por estrato, região sul do Estado de São Paulo, 1998-2003.

\begin{tabular}{|c|c|c|c|c|c|c|}
\hline \multirow[t]{2}{*}{ Estrato } & \multirow[t]{2}{*}{ Equídeos na UPA } & \multicolumn{2}{|c|}{ № de UPAs na amostra } & \multirow[t]{2}{*}{ Equinos } & \multirow[t]{2}{*}{ Asininos e muares } & \multirow[t]{2}{*}{ Equídeos } \\
\hline & & Total & $\begin{array}{c}\text { Com } \\
\text { equídeos }\end{array}$ & & & \\
\hline 0 & 0 & 2 & 1 & 2 & 1 & 3 \\
\hline 1 & 1 a 5 & 37 & 19 & 58 & 7 & 65 \\
\hline 2 & 6 a 20 & 7 & 7 & 52 & 9 & 61 \\
\hline 3 & 21 ou mais & 4 & 3 & 31 & 3 & 34 \\
\hline Soma & - & 50 & 30 & 143 & 20 & 163 \\
\hline
\end{tabular}

Fonte: dados da pesquisa. 
ça do vírus nos tecidos, como foi demonstrado experimentalmente por LETCHWORTH et al. (1996), ou ainda devido a presença de animais silvestres na região, uma vez que há relatos da presença de anticorpos em mamíferos selvagens (JiménEZet al.,1996). Artrópodes também poderiam ser outra fonte de manutenção do vírus na natureza, uma vez que o clima da região favorece a proliferação de insetos e o vírus já foi isolado de mosquitos dos gênerosPhlebotomus, Aedes e Simuliidae (MEAD et al., 2004).

Os resultados de soroprevalência obtidos no presente estudo sugerem a circulação do HVE, dos vírus da IE Equi-1(H7N7) e Equi-2 (H3N8), dos vírus EEE e VEE e dos vírus da estomatite vesicular Indiana 2 Cocal (COCV) e Indiana 3 - Alagoas (VSAV) no rebanho de equídeos do sul do Estado de São Paulo. A presença destes agentes envolve tanto a saúde dos equídeos como a saúde humana e alerta para a importância da adoção de medidas sanitárias que minimizem sua disseminação.

\section{REFERÊNCIAS}

ACHA NP, SZYFRES B. Zoonosis y enfermedades transmisibles comunes al hombre y a los animales. 3rd.ed. Washington (DC): Organizacion Panamericana de la Salud, 2003. v.2, p.201-210. (OPAS - Publicación Cientifica y Técnica 580),

ALLENDE, R.; GERMANO, P.M.L. Comparison of virus neutralization and enzime-linked immunosorbent assay for the identification of antibodies against vesicular stomatitis (Indiana 3) virus. Revue Scientifique et Technique de l'Office International des Épizooties, v.12, n.3, p.849-85், 1993.

BISSORDI, I.; LIMA, L.B.Q.; SUZUKI, A.; COIMBRA, T.L.M.; PETRELLA, S.M.C.N.; SOUZA, R.P.; FONSECA, B.A.L.; CUNHA, E.M.S.; VILLALOBOS, E.M.C.; NASSAR, A.F.C.; LARA, M.C.S.H.; PINO, F. Prevalence of Flavivirus antibodies in equidae in the south of Sao Paulo state, Brazil, 2004-2005. Prevalence of Flavivirus antibodies in equidae in the south of Sao Paulo state, Brazil, 2004-2005. Virus Revue Research, v.11, p.43-44, 2006. Suplemento 1

CUNHA, E.M.S.; DE FERRARI, C.I.; LARA, M.C.C.S.H.; SILVA, L.H.Q. Presença de anticorpos contra o herpesvírus equino 1 (HVE-1) em equinos do noroeste do Estado de São Paulo. Arquivos do Instituto Biológico, São Paulo, v.69, n.1, p.1-5, 2002.

DE STEFANO, E.; ARAÚJO, W.P.; PASSOS, E.C.; PITUCO, E.M. Pesquisa de anticorpos contra o vírus da Estomatite Vesicular em bovinos de corte criados na região de Araçatuba, Estado de São Paulo, Brasil em 2000. Brazilian Journal of Veterinary Research and Animal Science, v.40, p.29-35, 2003.
DIEL, D.G.; ALMEIDA, S.R.; WEIBLEN, R.; FRANDOLOSO, R.; ANZILIERO, D.; KREUTZ, L. C.; GROFF, F.H.S.; FLORES, E.F. Prevalência de anticorpos contra os vírus da influenza, da arterite viral e herpesvírus em equinos do Estado do Rio Grande do Sul, Brasil. Ciência Rural, v.36, n.5, p.1467-1673, 2006.

HEINEMANN, M.B.; CORTEZ, A.; SOUZA, M.C.C.; GOTTI, T.; FERREIRA, F.; HOMEM, V.S.F.; FERREIRA NETO, J.S.; SOARES, R.M.; SAKAMOTO, S.M.; CUNHA, E.M.S.; RICHTZENHAIN, J.L. Soroprevalência da anemia infecciosa equina, da arterite viral dos equinos e do aborto equino a vírus no município de Uruará, PA, Brasil. Brazilian Journal of Veterinary Research and Animal Science, v.39, n.1, p.50-53, 2002.

HEINEMANN, M.B.; SOUZA, M.C.C.; CORTEZ, A.; FERREIRA, F.; HOMEM, V.S.F.; FERREIRA NETO, J.S.; SOARES, R.M.; CUNHA, E.M.S.; RICHTZENHAIN, J.L. Soroprevalência da encefalomielite equina do leste e oeste no muinicípio de Uruará, PA, Brasil. Brazilian Journal of Veterinary Research and Animal Science, v.43, p.137-139, 2006. Suplemento.

HOLYOAK, G.R.; BALASURIYA, U.B.R.; BROADDUS, C.C.; TIMONEY, P.J. Equine viral arteritis: Current status and prevention. Theriogenology, v.70, n.3, p.403414, 2008.

INCRA. Cadastro de imóveis rurais. 2002. Disponível em: <http:// www.incra.gov.br>. Acessado em: 18 set. 2002.

IVERSSON, L.B.; COIMBRA, T.L.M. Encefalite na região do Vale do Ribeira, São Paulo, Brasil, no período pósepidêmico de 1978 a 1983. Revista de Saúde Pública, v.32, p.323-332, 1984.

IVERSSON, L.B.; SILVA, M.S.; TRAVASSOS DA ROSA, A.P.A.; BARROS, R.S.V. Circulation of Eastern equine encephalitis, Western equine encephalitis, Ilhéus, Maguari e Tacaiuma viruses in equines of the Brazilian Pantanal, South América. Revista do Instituto de Medicina Tropical, v.33, p.355-359, 1993.

JIMÉNEZ, A.E.; JIMÉNEZ, C.; CASTRO, L.; RODRIGUEZ, L. Serological survey of small mammals in a vesicular stomatitis virus enzootic area. Journal of Wildlife Diseases, v.32, p.247-249, 1996.

KISH, L. Survey sampling. New York: Wiley, 1965. 643p.

KOTAIT, I.; PEIXOTO, Z.M.P.; QUEIROZ, L.H.; CUNHA, E.M.S.; SOUZA, M.C.A.M.; MACRUZ, R.; FREITAS, C.A. Diagnóstico laboratorial do aborto equino a vírus através de imunofluorescência e soroneutralização. Revista de Microbiologia, v.20, n.1, p.128-132, 1989.

KOTAIT, I.; PEIXOTO, Z.M.P.; COIMBRA, T.L.M.; CUNHA, E.M.S.; QUEIROZ, L.H; MACRUZ, R.; 
NAGAMORI, A.H. Isolamento e identificação do vírus da encefalomielite equina, tipo leste, em equinos do Estado de São Paulo, Brasil. Arquivos do Instituto Biológico, São Paulo, v.59, n.1/2, p.37-41, 1992.

LARA, M.C.C.S.H.; FERNANDES, W.R.; BIRGEL, E.H. Prevalência de anticorpos antivírus da arterite dos equinos em cavalos criados no Estado de São Paulo. Arquivos Brasileiros de Medicina Veterinária e Zootecnia, v.54, n.3, p.223-227, 2002.

LARA, M.C.C.S.H.; BARROS FILHO, I.; VIANA, F.; GREGORY, L.; CUNHA, E.M.S.; CASTRO, A.F.; BIRGEL, E.H.; FERNANDES, W.R. Pesquisa de anticorpos contra o vírus da arterite dos equinos (VAE) e herpes equino tipo 1 (HVE-1) em cavalos criados em Curitiba, PR. A Hora Veterinária, v.23, n.135, p.26-28, 2003a.

LARA, M.C.C.S.H.; CUNHA, E.M.S.; NASSAR, A.F.C.; GREGORY, L.; BIRGEL, E.H.; FERNANDES, W.R. Ocorrência do herpesvírus equino 1 (HVE-1) em cavalos criados no Estado de São Paulo, Brasil. Ars Veterinária, v.19, n.3, p. 254-259, 2003 b.

LARA, M.C.C.S.H.; FURMAN, K.E.; BARROS FILHO, I.R.; VILLALOBOS, E.M.C.; CUNHA, E.M.S.; DECONTO, I.; BONACIM, J.; UTIME, R.A.; BIONDO, AW. Detection of antibodies against equine viral arteritis vírus (EVAV) and equine herpesvirus type 1 (EHV-1) in cart horses from Curitiba and surroudings, southern Brazil. Archives of Veterinary Science, v.11, n.3, p.11-14, 2006.

LETCHWORTH, G.J.; BARRERA, J.D.C.; FISHEL, J.R.; RODRIGUEZ, L.L. Vesicular Stomatitis New Jersey Virus RNA Persistis in Cattle Following Convalescence. Virology, v.219, n.2, p.480-484, 1996.

LOPES, O.S.; SACCHETA, A. Epidemiological studies on eastern equine encephalitis vírus in São Paulo, Brazil. Revista do Instituto de Medicina Tropical, v.16, n.5, p.253-257, 1974.

LOUREIRO, B.O.; GRANJA JUNIOR, J.O.; SCHIAVO, P.A.; OLIVEIRA, P.A.; PORTZ, C.; BRITO, S.N.; BITTENCOURT, A..J.; ANDRADE, C.M. Seroepidemiology of the virus of equine influenza, subtype A/equine-2 (H3N8), in the Rio de Janeiro's State - Brazil. Virus Revue Research, v.5, n.2, p.152, 2000. Suplemento.

MANCINI, D.A.P.; CUNHA, E.M.S; LARA, M.C.C.S.H.; MENDONÇA, R.M.Z.; DIAS, A.L.F., CASTRO, A.F.; PINTO, J.R.; MENDONÇA, R.Z. Evidence of humanequine interspecies influenza vírus transmission. Virus Revue Research, v.11, n.1/2, p.44-50, 2006.

MEAD, D.G.; GRAY E.W., NOBLET R.; MURPHY, M.D.; HOWERTH, E.W.; STALLKNECHT, D.E. Biological Transmission of Vesicular Stomatitis Virus (New Jersey Serotype) by Simulium vittatum (Diptera:
Simuliidae) to Domestic Swine (Sus scrofa). Journal of Medical Entomology, v.41, n.1, p.78-82, 2004.

MODOLO, J.R.; PETZOLDT, K.; GOTTS-CHALK, A.F.; MARGATHO, L.F.F.; FORLIN, W.; CARREIRA, E.L.C. Investigação sorológica do Herpesvirus equi-1 em equinos pelo teste de fixação de complemento, considerações sobre seu uso na saúde do haras. A Hora Veterinária, v.8, n.48, p.25-27, 1989.

NILSSON, M.R.; SUGAY, W. Ocorrência da encefalomielite equina em Itaporanga, estado de São Paulo. Arquivos do Instituto Biológico, São Paulo, v.29, p.63-68, 1962.

OKUDA, L.H.; JEREZ, J.A.; PITUCO, E.M.; DE STEFANO, E.; RODRIGUES, L.A. Estomatite vesicular: monitoramento em touros doadores de sêmen de uma central de inseminação artificial. Arquivos do Instituto Biológico, São Paulo, v.70, n.1, p.11-15, 2003.

OLIVEIRA, G.S; SCHIAVO, P.A.; MAZUR, C.; ANDRADE, C.M. Prevalência de anticorpos para o vírus da Influenza Equina, sub tipo H3N8, em equídeos apreendidos no Estado do rio de Janeiro. Ciência Rural, v.35, n.5, p.1213-1215, 2005.

ORGANIZAÇÃO MUNDIAL DE SAÚDE ANIMAL. OIE. Manual of diagnostic tests and vaccines for terrestrial animals. Equine influenza. Disponível em: <http://www.oie.int/eng/nomes/mmanual/ A_00083>. Acesso em: 9 jun. 2006.

ORGANIZAÇÃO MUNDIAL DE SAÚDE ANIMAL. OIE. World animal health situation-HANDSTAUS II. Disponível em: <http://www.oie.int/hs2/ report.asp?lang=en>. Acesso em: 19 set. 2007.

PINO, F.A. et al. (Orgs.). Levantamento censitário de unidades de produção agrícola do estado de São Paulo, 1995/1996. Ed. rev. e ampl. São Paulo: IEA/CATI/SAA, 2000. 1 CD-ROM.

PINO, F.A. Unidades amostrais em levantamento de dados agrícolas. Agricultura em São Paulo, v.50, n.1, p.19, 2003.

ROMANO-LIEBER, N.S.; IVERSSON, L. Inquérito soroepidemiológico para pesquisa de infecções por arbovírus em moradores de reserva ecológica. Revista de Saúde Pública, v.34, n.3, p.236-242, 2000.

REED, S.T.; TORIBIO, R.E. Equine herpesvirus 1 and 4. Veterinary Clinics of North America. Equine Practice, v.20, n.3, p.631-642, 2004.

SENNE, D.A.; PEARSON, J.E.; CARBREY, E.A. Equine viral arteritis: a standart procedure for the virus neutralization test and comparision of results of approficiency test performed at five laboratories. Proceedings of United State animal Health Association, v.89, p.29-34, 1985. 
SILVA, R.A.M.S.; DÁVILA, A.M.R.; IVERSSON, L.B.; ABREU, U.G.P. Equine viral diseases in the Pantanal, Brazil. Studies carried out from 1990 to 1995. Revue de Élevage de Médicine Véterinaire des Pays Tropicaux, v.52, n.1, p.9-12, 1999.

TESH, R.B.; BOSHELL, J.; MODI, G.B.; MORALES, A.A.; YOUNG, D.G.;CORREDOR, A. A.; CARRASQUILLA, C. F.; RODRIGUEZ, C.; WALTERS, L. L.; GAITAN,M. O.

Natural infection of humans, animals, and phlebotomine sand flies with the Alagoas serotype of vesicular stomatitis virus in Colombia. American Journal of Tropical Medicine and Hygiene, v. 6, n. 3, p. 653661, 1987.
VARGAS, A.C.; WEIBLEN, R. Prevalência de anticorpos contra herpesvírus equino tipo 1 (HVE 1) em equinos de alguns municípios do Estado do Rio Grande do Sul. A Hora Veterinária, v.10, n.59, p.5-8, 1991.

VASCONCELOS, P.F.C.; TRAVSSOS DA ROSA, J.F.S.; TRAVSSOS DA ROSA, A.P.A.; DÉGALLIER, N.; PINHEIRO, F.P.; SÁ FILHO, G.V. Epidemiologia das encefalites por arbovírus na Amazônia Brasileira. Revista do Instituto de Medicina Tropical, São Paulo. v.133, n.6, p.465-476, 1991.

Recebido em 10/12/07

Aceito em 17/3/09 